\title{
Hands-on Learning Activity Using an Apparatus for Transient Phenomena in RC Circuit Based on Arduino UNO R3-LINX-Labview
}

\author{
https://doi.org/10.3991/ijoe.v13i01.6317 \\ N. Suwondo and D. Sulisworo \\ Ahmad Dahlan University, Yogyakarta, Indonesia \\ dsw_uad@yahoo.com
}

\begin{abstract}
Integrating student-centered learning strategies and utilizing technology will improve learning performance. Hands-on learning strategies will reduce misconceptions and engage students in learning certain theories or concepts. Both are the reasons for this study. The aim of this study was to develop a learning apparatus based on ALL (Arduino UNO R3-LINX-LabView). The observed case is transient phenomena in an RC circuit through real time current and voltage wave chart characteristic of a charging and discharging capacitor with a semi-automatic control. The results showed that this apparatus offers a good opportunity to be used in physics learning. In the next study, this apparatus will be used with a specific learning strategy to find its effect on the student learning performance.
\end{abstract}

Index Terms-Arduino, education, hands-on learning, innovation, learning, LabView, microcontroller, physics, RC circuit, technology.

\section{Introduction}

The success of technology in the classroom is not determined by the technology itself but by how technology enables teaching and learning [1][2]. Integrating a studentcentered learning strategy and technology will improve learning performance [3]. Hands-on learning strategies will engage students' learning of certain theories or concepts [4][5], reasons for the strategies in some universities being changed regarding physics learning [6][7]. However, in the application of this change, there are some constraints because of relatively expensive lab equipment or apparatus. Fortunately, innovations in information technology are providing new and cheaper opportunities and a good degree of accuracy in equipment available for learning. One of the possibilities is the integration of Arduino-LINX- LabVIEW (ALL) for learning [8][9][10]. Some of the advantages of ALL-based learning apparatus development are it is cheaper, simpler, and able to describe the observed phenomenon well. These advantages are very suitable for learning.

One of the most important physics concepts in the area of electricity is the transient phenomenon in the resistor-capacitor circuit ( $\mathrm{RC}$ circuit). This dynamic phenomenon is abstract, and the use of manual apparatus to observe it requires skill. It is not a simple activity for students and needs considerable time. Real-time visualization of transient 
Short Paper-Hands-on Learning Activity Using an Apparatus for Transient Phenomena in RC Circuit Based on Arduino UNO R3-LINX-Labview

symptoms based on information technology is easier and its attractive appearance will engage students and improve their understanding of the concept.

Development of characteristics similar to that device is possible using an Arduino platform as an alternative to meet the learning requirements. An Arduino platform has been used on physics experiments apparatus in many activities, for instance on damped oscillations [11], low cost-scientific instrumentation based on open-source [12], and simple harmonic oscillation [13]. The study of RC transient symptoms is in unreal-time graphics [14] as well as in real-time graphics [15] but still uses relatively expensive apparatus. This research developed an apparatus for the transient phenomena in an RC circuit based on Arduino UNO R3-LINK-LabView, which is cheaper and has good accuracy for learning activities.

\section{Theoretical Background}

An RC circuit is an electric circuit consisting of a resistor and capacitor driven by a current source. It is known as an RC filter or RC network. This is the simplest type of $\mathrm{RC}$ circuit. For this research, the RC circuit is shown in Figure 1. An RC circuit can be used to filter the signal by blocking a specific frequency and passing others. Two of the most common RC filters are the high-pass filter and the low-pass filter; the filter bandpass and the band-stop filter usually require an RLC filter.

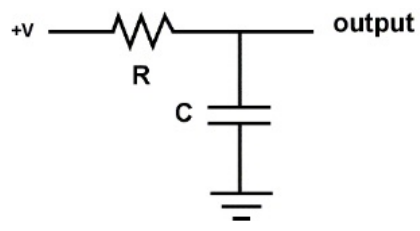

Fig. 1. Series RC circuit

Charging the capacitor will happen if the left leg of the resistor is connected to a voltage source. Discharging an electrical charge in the capacitor occurs when the left leg is a resistor connected to a ground.

Equations (1) and (2) represent the voltage of the charging and discharging capacitor processes, respectively.

$$
\begin{gathered}
V_{c}(t)=V\left(1-e^{-\frac{t}{R C}}\right) . \\
V_{c}(t)=V_{c}(0) e^{-\frac{t}{R C}}
\end{gathered}
$$

Equations (3) and (4) represent the current of the charging and discharging capacitor processes, respectively.

$$
\begin{gathered}
I_{c}(t)=\frac{V}{R} e^{-\frac{t}{R C}} \\
I_{C}(t)=-\frac{V_{c}(0)}{R} e^{-\frac{t}{R C}}
\end{gathered}
$$

where 
Short Paper-Hands-on Learning Activity Using an Apparatus for Transient Phenomena in RC Circuit Based on Arduino UNO R3-LINX-Labview

$V_{c}(t) \quad$ voltage as function of time

$I_{c}(t) \quad$ current as function of time

$V \quad$ source voltage

$V_{c}(0)$ initial voltage of capacitor

$R \quad$ value of resistor

$C \quad$ value capacitor

The capacitor voltage can be measured directly, as shown in Figure 1. The value of the current can be calculated further using the Ohm principle. Data fitting can be performed using equations (1) to (4).

\section{$3 \quad$ Method}

\subsection{Equipment and Material}

The current study used an electrolytic capacitor and resistor with a value such that the charging and discharging process could be observed across time. A potentiometer resistor was selected to represent the resistor so the conversion value was easy to calculate. Figure 1 was modified to obtain the required data and became Figure 3 below.

An Arduino UNO R3 controlled via a laptop was used to read the voltage. The Arduino board has a lot of digital and analog pins. In this study, a clone board of an Arduino UNO R3 was used because it is cheaper. Another important control of this study was the removal process of charging to discharging and vice versa. IC series 74LS14 was used as the digital inversion and CD4066 as the digital switch. For practical reasons, an installation breadboard rope and jumper cables were used to integrate the material.

The main software was LabVIEW, which is widely used internationally. It is easy to use and has good graphic facilities, several control components, and an available free version. To simplify programming, the Arduino board using LabVIEW LINX firmware was used as an interface. Therefore, it did not need an Arduino IDE anymore.

CurveExpert Basic was used for data fitting. It is free software. Using this software, the parameter fitting represented in equations (1) to (4) could be performed. The fitting model of voltage on charging and discharging of the capacitor are respectively shown below in equations (5) and (6).

$$
\begin{gathered}
y=a\left(1-e^{-b x}\right) \\
y=a e^{-b x}
\end{gathered}
$$

Furthermore, the current fitting model on charging and discharging of the capacitor is shown in equations (7) and (8).

$$
\begin{gathered}
I_{c}(t)=\frac{V}{R} e^{-\frac{t}{R C}} \\
y=a e^{-b x} \\
y=-a e^{-b x}
\end{gathered}
$$


Short Paper-Hands-on Learning Activity Using an Apparatus for Transient Phenomena in RC Circuit Based on Arduino UNO R3-LINX-Labview

This study also compared the data quality on slow data acquisition, $250 \mathrm{mS}$ or $4 \mathrm{~Hz}$ and $50 \mathrm{mS}$ or $20 \mathrm{~Hz}$. The suitable time for data acquisition could be decided using the comparison results.

\subsection{Apparatus Configuration}

The configuration of the instruments and software for this study is shown in Fig. 2.

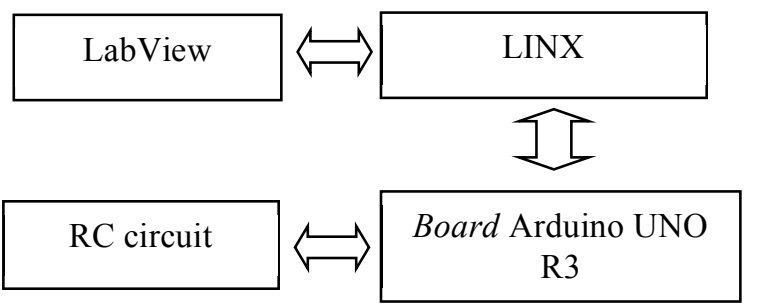

Fig. 2. Block diagram of apparatus configuration

\section{$4 \quad$ Result And Discussion}

\subsection{Result}

The complete configuration of the electronic circuit apparatus is shown in Figure 3.

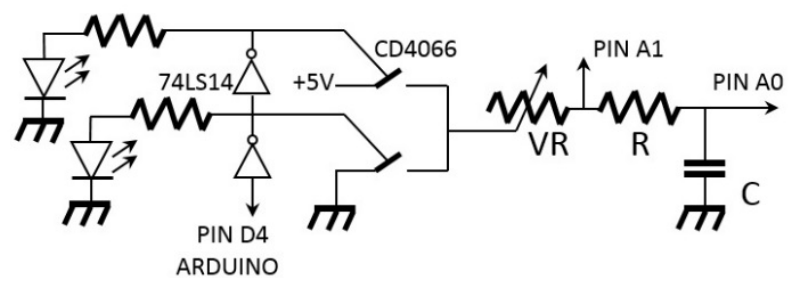

Fig. 3. Electronic circuit apparatus

Using the collected data, the current of the capacitor is equal to the voltage of R divided by the value of $\mathrm{R}$. The fritzing diagram, as seen in Figure 4, shows a scheme of the connection between the equipment and materials. A real picture of the apparatus configuration is shown in Figure 5. See the breadboard for the instrument connections. All instrument interaction of the transient phenomena in the RC circuit based on ALL can be traced on the block diagram captured from the LINX software as shown in Figure 6.

Figure 7 shows the capture of the current and voltage while charging and discharging the capacitor. It is configured to collect data every $50 \mathrm{mS}$. From the graphics, the characteristic of the phenomena can be analyzed. The curves represent the current and voltage dynamics of the charging and discharging of the capacitor. One of the fitting results of the data is shown in Figure 8, especially for voltage value on the capacitor charging. 
Short Paper-Hands-on Learning Activity Using an Apparatus for Transient Phenomena in RC Circuit Based on Arduino UNO R3-LINX-Labview

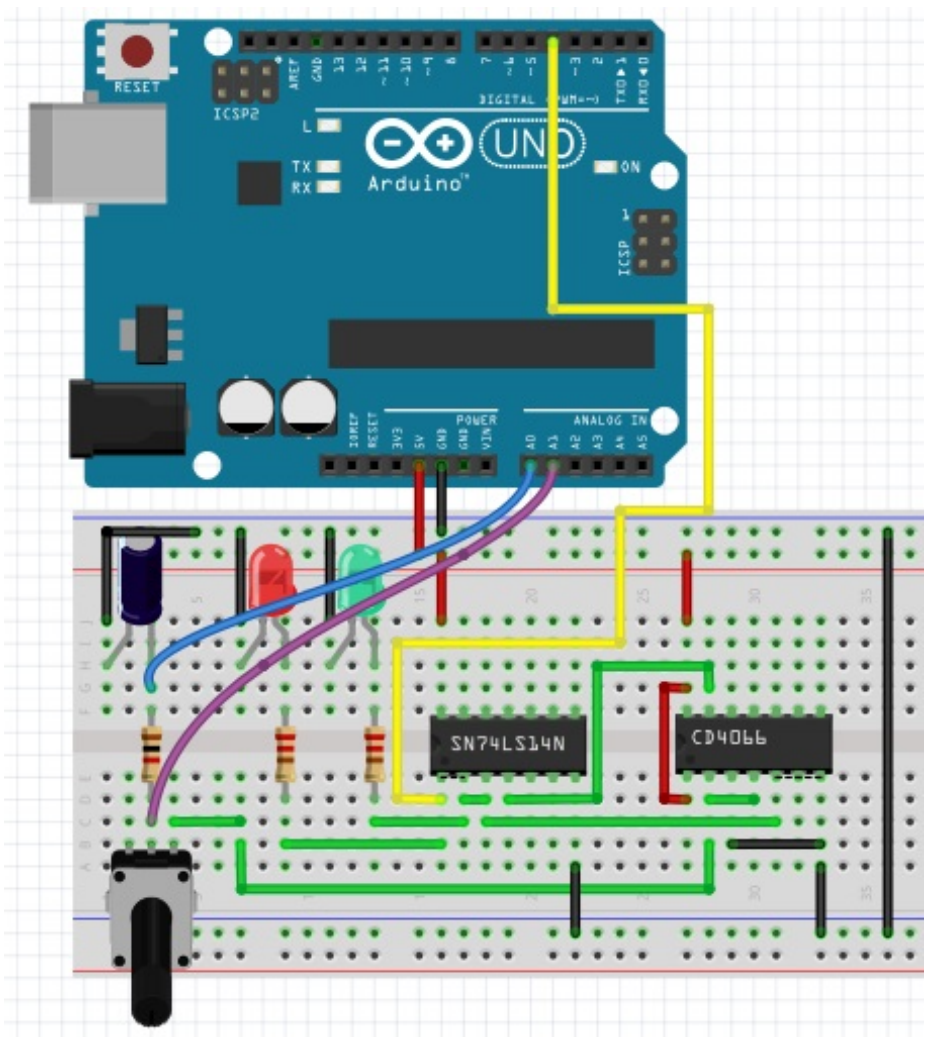

Fig. 4. The fritzing diagram of the apparatus

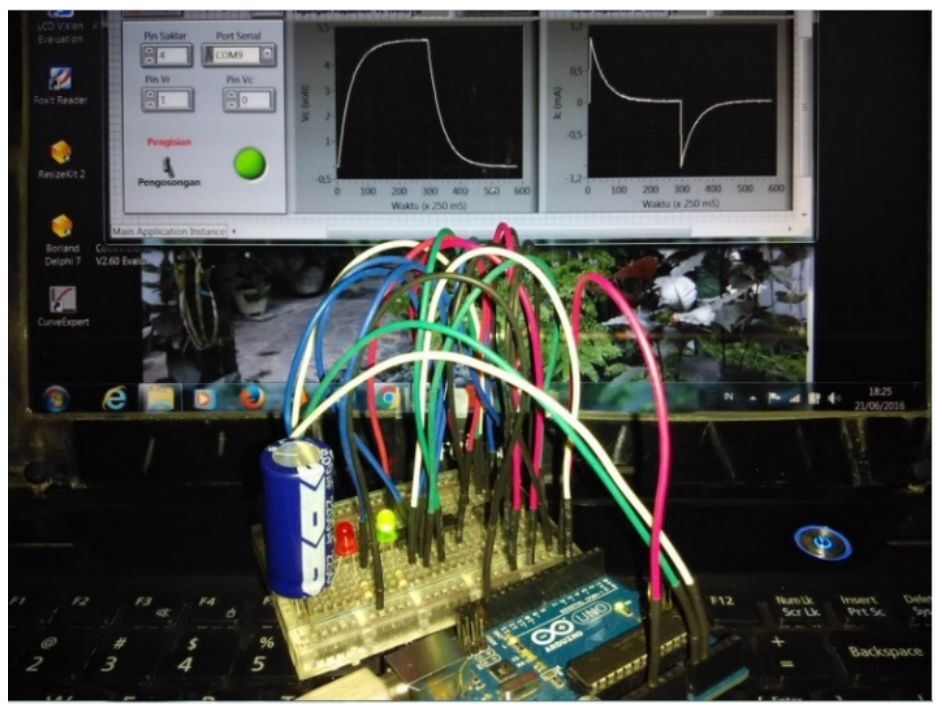

Fig. 5. The real picture of the apparatus 
Short Paper-Hands-on Learning Activity Using an Apparatus for Transient Phenomena in RC Circuit Based on Arduino UNO R3-LINX-Labview

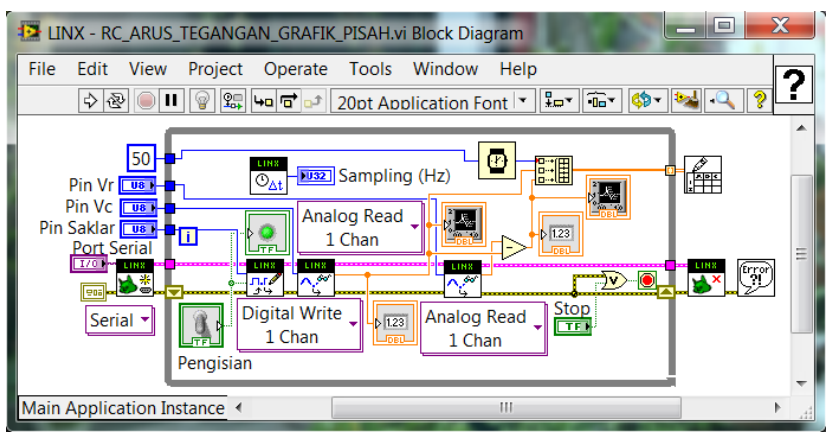

Fig. 6. The capture of Linx-LabView block diagram

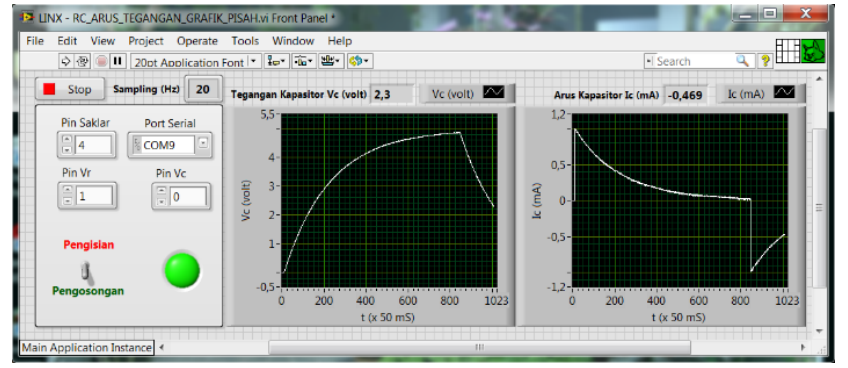

Fig. 7. The capture of current and voltage graphic on charging and discharging process

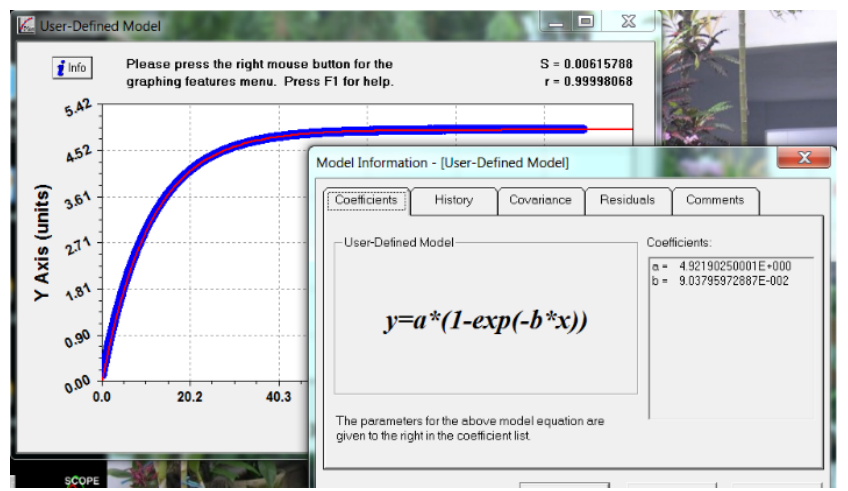

Fig. 8. The capture of fitting result using CurveExpert

Based on the measurement results using digital ohmmeter kaise SK-6222, the value of the potentiometer resistor is $3.78 \mathrm{k} \Omega$ and the value of resistor $\mathrm{R}$ is $1 \mathrm{k} \Omega$. The value of the capacitor is $2200 \mu \mathrm{F}$. The source voltage is $5 \mathrm{~V}$. Considering the time sequence for data acquitition is $50 \mathrm{mS}$ as shown in Figure 7, then the value of $a$ and $b$ in equations (5) and (6) can be calculated. The results are $5.0 \mathrm{~V}$ and $0.0950 \mathrm{~S}^{-1}$. While the value of $a$ and $b$ in equations (7) and (8) are $0.0010 \mathrm{~A}$ and $0.0950 \mathrm{~S}^{-1}$, those values are used as references for the fitting process of data acquisition for the current and voltage during the charging and discharging of the capacitor. Table 1 shows the results of $a$ and $b$ based on equations (5), (6), (7) and (8). 
Short Paper-Hands-on Learning Activity Using an Apparatus for Transient Phenomena in RC Circuit Based on Arduino UNO R3-LINX-Labview

Table 1. The fitting result for sequence time $50 \mathrm{mS}$

\begin{tabular}{|c|c|c|c|c|}
\hline Voltage & \multicolumn{2}{|c|}{ Charging } & \multicolumn{2}{c|}{ Discharging } \\
\hline Process & $a$ & $b$ & $a$ & $b$ \\
\hline Coefficient & $V$ & $S^{-}$ & $V$ & $S^{l}$ \\
\hline Unit & 5 & 0.095 & 5 & 0.095 \\
\hline Reference Value & 4.921 & 0.090 & 4.937 & 0.090 \\
\hline Data & 1.58 & 4.95 & 3.26 & 5.20 \\
\hline Deviation (\%) & \multicolumn{3}{|c|}{0.999} & \multicolumn{2}{|c|}{0.994} \\
\hline Correlation & \multicolumn{3}{|c|}{} \\
\hline
\end{tabular}

Current

\begin{tabular}{|c|c|c|c|c|}
\hline Process & \multicolumn{2}{|c|}{ Charging } & \multicolumn{2}{c|}{ Discharging } \\
\hline Coefficient & $a$ & $b$ & $a$ & $b$ \\
\hline Unit & $A$ & $S^{-1}$ & $A$ & $S^{-1}$ \\
\hline Reference Value & 0.001 & 0.095 & 0.001 & 0.095 \\
\hline Data & 0.00095 & 0.087 & 0.00097 & 0.089 \\
\hline Deviation (\%) & 4.80 & 7.64 & 3.00 & 5.41 \\
\hline Correlation & \multicolumn{2}{|c|}{0.994} & \multicolumn{2}{c|}{0.994} \\
\hline
\end{tabular}

Shortly, for the sequence time $250 \mathrm{mS}$, the deviation of $a$ value ranges from $0.2 \%$ to $7.5 \%$ and $8 \%$ to $16 \%$ for $b$ value. Correlation $r$ is in the range of 0.963 to 0.999 . It means that this apparatus showed good performance. It can be used as an instrument for a student laboratory activity. Based on the results of this study, the correspondence between the calculated parameter using the collected data and the reference values is good for a $50 \mathrm{mS}$ case. The results of this calculation are presented in Table 1 .

\subsection{Discussion}

At first, the assembling process using a jumper looked too complicated. But the simple circuit makes assembly easier. In this study, connecting the instruments using a jumper is merely to simplify setting up and breaking down the apparatus configuration. On the other hand, the assembly process is a part of the activity to increase students' motoric skills. The activity during this study revealed that adding the automatic capacitance measurement unit and the automated charging and discharging, the capacitor will improve the system's performance. The focus is on observation of the phenomena. If the students are unmotivated at first, it will influence their engagement during their learning.

Even though the apparatus showed good performance, teachers should pay attention to the selection of learning strategies. As stated at the beginning of this paper, technology is a tool to enable learning. Based on a previous study, the personalized learning environment has the possibility of utilizing this learning apparatus for physics learning. The new learning approach should be modeled to identify the benefit of this learning apparatus.

On the one side, Arduino offers many opportunities to be diversified in others areas by adding various sensors and features. This apparatus can be developed into a prop for the various dynamics of current or voltage of a capacitor circuit combined with other components, such as diodes and op-amp. It also can be modified into a generated waves device, differentiator circuit, integrator, filter, or more. But this study focused on the learning implementation first. 
Short Paper-Hands-on Learning Activity Using an Apparatus for Transient Phenomena in RC Circuit Based on Arduino UNO R3-LINX-Labview

\section{Conclusion}

This study showed that the learning apparatus development using ALL for observation of transient phenomena in an RC circuit offers good possibilities for student learning. The data from the experiment using this apparatus can be calculated and analyzed properly and showed good performance. The characteristics of an RC circuit, including dynamic graphs of current and voltage of the capacitor charging and discharging in real-time, can be observed. Additionally, this device can be assembled more cheaply, more easily, and more simply. LINX-LabVIEW as a part of this apparatus contributes to the quite interesting interface. In general in the next study, all benefits of this apparatus should be implemented to find the effect of the learning strategy to enhance student learning performance.

\section{References}

[1] McKnight, K., O'Malley, K., Ruzic, R., Horsley, M. K., Franey, J. J., \& Bassett, K. (2016). Teaching in a digital age: how educators use technology to improve student learning. Journal of Research on Technology in Education, 1-18. https://doi.org/10.1080/15391523.2016.1175856

[2] Han, S., Capraro, R., \& Capraro, M. M. (2015). How science, technology, engineering, and mathematics (STEM) project-based learning (PBL) affects high, middle, and low achievers differently: The impact of student factors on achievement. International Journal of Science and Mathematics Education,13(5), 1089-1113. https://doi.org/10.1007/s10763-014-9526-0

[3] Henrie, C. R., Halverson, L. R., \& Graham, C. R. (2015). Measuring student engagement in technology-mediated learning: A review. Computers \& Education, 90, 36-53. https://doi.org/10.1016/ j.compedu.2015.09.005

[4] Rolston, J. S., \& Cox, E. (2015). Engineering for the real world: Diversity, innovation and hands-on learning. In International Perspectives on Engineering Education (pp. 261-278). Springer International Publishing. https://doi.org/10.1007/978-3-319-16169-3 13

[5] Brinson, J. R. (2015). Learning outcome achievement in non-traditional (virtual and remote) versus traditional (hands-on) laboratories: A review of the empirical research. Computers \& Education, 87, 218-237. https://doi.org/10.1016/j.compedu.2015.07.003

[6] Hinko, K. A., Madigan, P., Miller, E., \& Finkelstein, N. D. (2016). Characterizing pedagogical practices of university physics students in informal learning environments. Physical Review Physics Education Research, 12(1), 010111. https://doi.org/10.1103/PhysRevPhysEducRes.12.010111

[7] Ekmekci, A., \& Gulacar, O. (2015). A case study for comparing the effectiveness of a computer simulation and a hands-on activity on learning electric circuits. Eurasia Journal of Mathematics, Science \& Technology Education, 11(4), 765-775.

[8] Kuan, W. H., Tseng, C. H., Chen, S., \& Wong, C. C. (2016). Development of a Computer-Assisted Instrumentation Curriculum for Physics Students: Using LabVIEW and Arduino Platform. Journal of Science Education and Technology,25(3), 427-438. https://doi.org/10.1007/s10956-016-9603-y

[9] Souza, M. A., \& Duarte, J. R. (2015). Low-cost educational robotics applied to physics teaching in Brazil. Physics Education, 50(4), 482. https://doi.org/10.1088/0031-9120/50/4/482

[10] Hernández, D., Trejo, H., \& Ordoñez, E. (2015). Development of an exploration land robot using lowcost and Open Source platforms for educational purposes. In Journal of Physics: Conference Series (Vol. 582, No. 1, p. 012007). IOP Publishing. https://doi.org/10.1088/1742-6596/582/1/012007

[11] de Castro, L. H. M. , Lago, B. L., Mondaini, F. (2015). Damped Harmonic Oscillator with Arduino. Journal of Applied Mathematic and Physics, Vol. 3, pp. 631-636. https://doi.org/10.4236/ jamp.2015.36075

[12] Fisher, D. K., Gould, P. J. (2012). Open-Source Hardware is a Low-Cost Alternative for Scientific Instrumentation and Research. Modern Instrumentation, Vol. 1, pp. 8-20. https://doi.org/10.4236/mi. $\underline{2012.12002}$

[13] Galeriu, C., Edwards, S., Esper, G. (2014) An Arduino Investigation of Simple Harmonic Motion, The Physics Teacher, Vol. 52, pp. https://doi.org/10.1119/1.4865518 
Short Paper-Hands-on Learning Activity Using an Apparatus for Transient Phenomena in RC Circuit Based on Arduino UNO R3-LINX-Labview

[14] Huang, B. (2015) Open-source Hardware - Microcontrollers and Physics Education - Integrating DIY Sensors and Data Acquistion with Arduino, 122nd ASEE Annual Conference \& Exposition, June 14-17, 2015, Seattle, WA, Paper ID \#14073.

[15] Galeriu, C., Letson, C., Esper, G. (2015) An Arduino Investigation of the RC Circuit, The Physics Teacher, Vol. 53, 285. https://doi.org/10.1119/1.4917435

\section{$7 \quad$ Authors}

N. Suwondo is senior lecturer at Physics Education Study Program of Ahmad Dahlan University, Jl. Prof. Supomo, Janturan, Yogyakarta, 55164 Indonesia (e-mail: nsuwondo@gmail.com).

D. Sulisworo has expertise on educational technology and as scholar at Graduate Program of Ahmad Dahlan University, Jl. Pramuka No. 42, Yogyakarta 55161, Indonesia (e-mail: dwi.sulisworo@uad.ac.id).

Submitted 05 October 2016. Published as resubmitted by the authors 11 November 2016 . 